\title{
INTEGRATING RADIO FREQUENCY IDENTIFICATION TECHNOLOGY IN ACADEMIC MANAGEMENT SYSTEM
}

\author{
${ }^{1}$ Zainab Rasheed Mirza and ${ }^{2} M$. Nawaz Brohi \\ ${ }^{1}$ Department of Research and Development, Al Madad Eng. Services Ajman, UAE \\ ${ }^{2}$ Department of Computing, SZABIST Dubai Campus, UAE
}

Received 2013-09-24; Revised 2013-09-28; Accepted 2013-11-21

\begin{abstract}
The purpose of this study is building a web and windows based intelligent system using web technologies, biometric and Radio Frequency Identification technologies (RFID) to strengthen an Academic Management System (AMS) in a campus for monitoring and improving academic performance of teachers and students. A campus mobile phone application will allow guardians to monitor student's movement history at campus, e-payments and food choices at canteen, class attendance, exam attendance and academic performance on daily basis. Mobile application for students will allow students to view their class schedules, teacher appointments, e-payment statement, warnings or announcements, locate their exam halls and search for classrooms.
\end{abstract}

Keywords: Biometric, Radio Frequency Identification, Academic Management System, Finger Print

\section{INTRODUCTION}

Education is always paid more attention for the development of society. Academic administration is very important in education, as accurate and fast data for each student's current academic state and performance is required by guardians, faculty and administration for taking decisions. As academic campuses are expanding quick and strong administration is becoming difficult for which many technologies are available.

Radio Frequency Identification is one of the leading edge technologies which can be integrated to existing systems in order to get more accurate data and faster retrieval. This study proposes an overview of RFID assisted smarter campus systems for students, faculty, management and guardians as well. In proposed system each faculty, staff and student will be carrying an RFID card while RFID readers will be installed all over the campus. At campus entrance each person's identification will be confirmed and verified with RFID card and finger print. RFID readers will be installed in all campus areas including classrooms, laboratories, cafeteria, library and also campus outdoor areas like car parking, play area for verifying faculty or student identification which will allow individual tracking and will also be helpful for reducing unwanted access of university resources.

Faculty and students RFID cards will be used for class room attendance, access control to the university resources, for borrowing library items, any e-payments at campus cafeteria, stationery or library, using transportation services, car parking, sign on in a computer system in labs, visiting any administration offices and locating classroom or exam halls.

Faculty will be able to locate students present at university but not attending class. Students looking for faculty will be able to track teacher or get an appointment. Examination attendance can be recorded with portable RFID readers. Administration offices need not to key in student ID number for student details instead student will place his RFID card over a reader and his information will pop up on screen.

Administration will be able to track not only student's activities and academic performance but also monitor Corresponding Author: Zainab Rasheed Mirza, Department of Research and Development, Al Madad Eng. Services Ajman, UAE 
teacher's academic performance by monitoring class timings, number of lectures given per subject, duration of lecture class, or any out of class assignment. No student will be allowed to leave campus during campus hours without seeking permission from their guardian.

For development of this project Microsoft SQL server will be used as a backend for databases and Microsoft. NET technologies will be used for development of windows application and web applications due to their various advantages.

In Fig. 1 overview of the proposed university management systems integrated with RFID technology has been shown which consists of three main systems student management system, faculty and staff management system and Visitor management system. All these system have used RFID tehnology in various ways.

\subsection{Implementation of RFID}

Violino (2005) describes that RFID is an enabling technology, which means it doesn't provide much value of its own but it enable companies to develop application that created value. RFID provide a means of effecting business transactions in a flexible, secure, standard way with minimal human intervention.

Ansari et al. (2011) report that radio waves are used for communication between RFID tag and reader; therefore no wires or line of sight is required. An RFID chip with an antenna is embedded in any physical object called RFID tag which can be read/write by a RFID reader/writer. Nainan et al. (2013) discuss that there are two types of RFID tags, passive tags get charged by the reader and active tags send information to reader.

Jiang and Li (2012) outline that implementing RFID technology for identification is cheaper and faster than other contact or non contact attendance technologies. In this study passive RFID tags will be used as they are comparatively cheaper and have long life than active RFID tags. RFID tags can be read through other materials like from inside a purse, wallet and within in the distance of three inches.

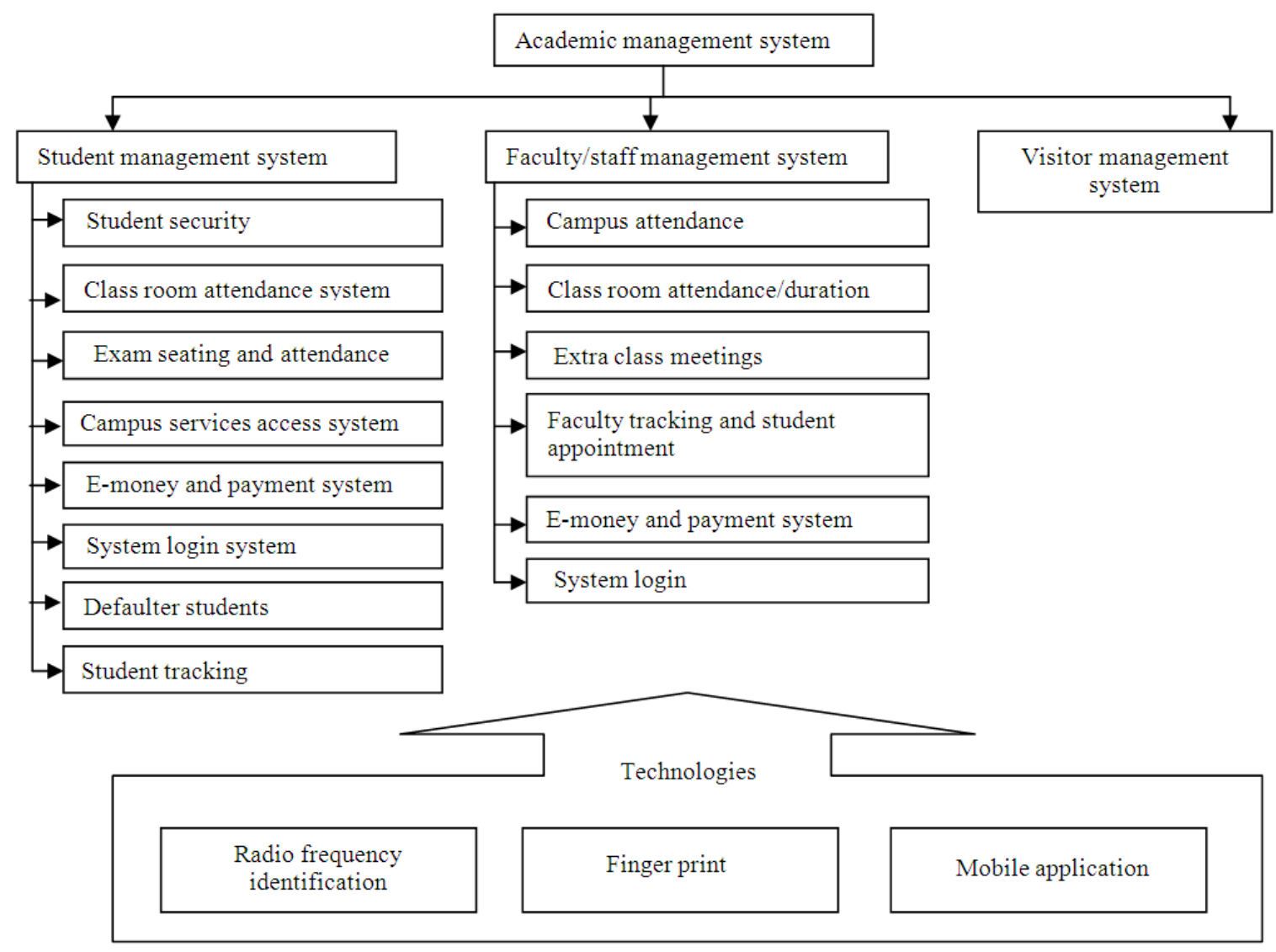

Fig. 1. Overview of academic management system 
Wahab et al. (2010) report that RFID allows smooth passing in or out of student as multiple tags can be detected at same time, therefore does not require queuing for identification. RFID improve campus security by allowing restricted access to various resources or campus areas at different times for different people according to administration requirements.

When an RFID tag is detected in all over a campus student name and picture will be displayed on networked computer system loaded from server. RFID readers connected all over campus will not need continues monitoring instead if any RFID reader is not working, server will send an auto message to the maintenance department defining RFID problem along with location.

\section{IMPLEMENTATION OF FINGER PRINT}

For individual identity, biometric uses finger print as they are unique and lifelong unchanged. Three types of fingerprint scanners are optical, ultrasonic, active and passive capacitance.

Fingerprint identification improves security at campus environment and reduces cheating in attendance until someone uses a fingerprint membrane to cheat the system, but the cost of implementing fingerprint all over campus is high while recognition speed is much slower than RFID, may require queuing in large class rooms.

Finger print scanner will be used as a biometric device for individual identification at campus entrance. After confirming individual finger print identification individual RFID card will be activated to use in the campus which again will be deactivated once the individual leaves the campus. As concluded by Ansari et al. (2011) that double verification will allow avoiding cheating to the system by mishandling of RFID cards.

\section{IMPLEMENTATION OF MOBILE APPLICATION}

Mobile phones now are not just limited to calling and sending messages but have become gadgets and made life easier. Mobile applications are internet applications designed to run on smart phone, tablets and other mobile devices. They allow various businesses to increase their revenue and also get connected to international market. According to Walters (2011) mobile apps give faster and easier access to wider audience, become a marketing tool and allow sending volume of information.

According to The International Telecommunication Union $77 \%$ of world population is online. As Walters
(2011) states that our impatient new generation wants something they want it now. Instead of waiting on PC to boot up and get connected to internet, using a mobile application is preferred. Any business can provide their services and offers on a convenient mobile application and get in touch with their clients.

Mobile application will allow faculty and students to get connected even out of the campus. Students can check their examination marks, e-money statement, class schedule, attendance status, view library catalog, track faculty, send emergency leave notification and locate their exam halls and class rooms. Faculty can track students missing from class, get in touch with students, check class timings guardians can track student's activities and check their academic performance in campus.

\section{STUDENT MANAGEMENT SYSTEM}

As implemented by Qiu et al. (2012), RFID readers all over the campus will send the student data to central student database server and enter in individual student profile. Student academic performance will show a summary of student activities all over campus.

\subsection{Student Security}

At campus building entrance each student will have double verification with RFID reader and Biometric to prevent disciplinary action both while leaving or entering the campus. Students who want to leave campus during campus hours will have to get authorization from student administration office who will seek permission from student's guardians. In this way guardian will be satisfied for their child's security during campus hours.

\subsection{Class Room Attendance}

Student attendance is a key factor for improving student academic performance which will be maintained by this system through their RFID cards. While entering and leaving class each student RFID card will be read by reader and student details will be shown on screen with a addition to total number of student present. Total number can be used by teachers in case teacher wants to do a headcount in classroom. System will allow only registered student for a class, mark class attendance, track and send messages to students leaving class before time, students not appearing in class while being in campus and students not attending campus without prior notification. Students will be able to locate their classroom on their mobile phones and send notification to their teachers in case they are not attending class. 


\subsection{Examination Seating and Attendance}

Students coming for examination can get their exam hall details on their mobile application highlighted on campus map and students need not to take hall ticket for being authorized to give exam instead as soon as they enter exam hall their RFID card will be read by RFID reader and their seat number with exam details will be displayed. If student profile has any problem student will have to visit student administration office. Student missing from exams will be sent an auto message while names with course names will be sent to student administration office.

\subsection{Campus Services Access}

Student RFID cards will allow using any campus services including car parking, library, cafeteria, stationery, outdoor play area, gymnasium unauthorized or defaulter students will not be allowed to access campus services instead will have to visit student administration office.

After entering the campus student ID card will be used for accessing any campus resources, each time student ID card is read student picture with other details will be displayed on computer system connected to RFID reader. System will allow administration to control security of various campus areas and different times. In case if any student has permission to access certain campus resources after campus hours this can be added to student profile and student RFID card will work accordingly. This will not allow the user to use and university resources after handing individual ID card to anyone else.

\subsection{E-money and Payment System}

Each student can add electronic credits to their RFID cards through student administration offices. This emoney will be used for purchasing items at cafeteria, vending machines, getting stationery items/services, or using transport service. Continues Transport users will use ID card for identification but one time transport users may pay to transport department. Through cafeteria we can monitor student's food preferences. E-money can also be used as an offer like student will get credit from campus for doing certain tasks.

\subsection{System Login}

Students will use their RFID cards for single sign on any lab computers and use their data on shared network drive. While visiting administration office reading students RFID card will popup student profile on computer system.

\subsection{Defaulter Students}

System can be sent auto messages and will be stopped for any further e-money transactions or using any campus services until they report to student administration office. RFID cards for student can be blocked to access campus areas in case of any academic offence. Administration can restrict university attendance of dismissed students or unwanted visitors. Any misconduct by student will result in unsatisfactory academic record.

\subsection{Student Tracking}

Mobile phone application or online website will allow guardians to track and monitor student at campus by checking student's e-money usage, campus resources usage, class attendance, duration of stay in various areas of campus and get student current location by retrieving last recorded location of student at campus.

\section{FACULTY AND STAFF MANAGEMENT SYSTEM}

\subsection{Class Room Duration}

Each faculty when reaches the classroom faculty ID card will be read and class will be auto started according to the class timetable. Teacher will again swipe ID card once class is finished. In this way each class timings and duration will be record for each subject and each teacher. This will be helpful for monitoring faculty's academic performance.

\subsection{Extra Class Meetings}

Teacher will notify the administration in case if teacher is taking any extra class or has any out of class meeting with students. Administration will update class details in AMS for automatic attendance.

\subsection{Faculty Tracking and Student Appointment System}

Will allow administration to track faculty and check their current location in case if faculty without disturbing faculty by calling during lecture or meeting. System can check teacher's availability and book and appointment for student with selected teacher.

\subsection{System Login}

Faculty and staff RFID card will be used for system login on any computer all over campus, using shared drive or visiting administration offices. 


\subsection{Visitor's Management System}

Visitors will be directly taken to administration offices. In case visitors want to visit the campus they will be given a temporary RFID card which they can use for specific time or for limited area or services. In case if we have visitors who will be using campus indoor play area or library for certain number of days and RFID card can be given which will restrict their access according to set requirements. Every day record of visitors visit will be saved in database for future references and can be used for marketing.

\section{FUTURE WORK}

There is always space of improvement in every system. Mobile application can be used in for students to pay course fee or transfer e-credits in RFID card and instead a student searches for any faculty member in campus, student can have a video conversation with faculty through mobile application. Maximum securities will be implemented to avoid any violation of academic standards. RFID technology scalability can be improved and performance can be boosted if combined with leading edge technology of Cloud computing.

\section{CONCLUSION}

In this study, a design of an intelligent academic management system is proposed which will strengthen daily management and eases supervision of student from when they arrive until when they leave even after campus hours. This system will integrate one of the fastest growing segments of IT, RFID technology, biometric technology and mobile applications to existing academic management system and provide more fast and easy to access to student profiles. In each student profile student complete history of purchases and attendance along with academic performance will be stored. This designed system will reduce manual effort, time consuming and repetitive tasks and human made mistakes and improve the system security.

\section{REFERENCES}

Ansari, A.N., A. Navada, S. Agarwal, S. Patil and B.A. Sonkamble, 2011. Automation of attendance system using RFID, biometrics, GSM modem with. Net framework. Proceedings of the International Conference on Multimedia Technology, Jul. 26-28, IEEE Xplore Press, Hangzhou, pp: 2976-2979. DOI: 10.1109/ICMT.2011.6002032

Jiang, L. and Y. Li, 2012. Attendance technology on campus research and application. Proceedings of the National Conference on Information Technology and Computer Science, (TCS' 12), Atlantis Press, pp: 40-42.

Nainan, S., R. Parekh and T. Shah, 2013. RFID technology based attendance management system. Int. J. Comput. Sci. Iss., 10: 516-521.

Qiu, Y., J. Chen and Q. Zhu, 2012. Campus access control system based on RFID. Proceedings of the IEEE 3rd International Conference Software Engineering Service Science, Jun. 22-24, IEEE Xplore Press, Beijing, pp: 407-410. DOI: 10.1109/ICSESS.2012.6269491

Violino, B., 2005. RFID business application. RFID J.

Wahab, M.H.A., A.A. Mutalib, H.A. Kadir and M.F.M. Mohsin, 2010. Design and development of portable RFID for attendance system. Proceedings of the International Conference Information Retrieval Knowledge Management, Mar. 17-18, IEEE Xplore Press, Shah Alam, Selangor, pp: 173-178. DOI: 10.1109/INFRKM.2010.5466925

Walters, D., 2011. The advantages of mobile Apps. Infomedia, Inc. 